\title{
Caracterização geológica - geofísica da porção central do Amapá com base em processamento e interpretação de dados aerogeofísicos
}

\author{
Lucíola Alves Magalhães ${ }^{1}$, Carlos Roberto de Souza Filho ${ }^{1}$ \& Adalene Moreira Silva ${ }^{2}$
}

\begin{abstract}
Resumo Este artigo aborda o processamento e a interpretação de dados aerogeofísicos (magnetometria e gamaespectrometria) de alta resolução espacial e densidade de amostragem (Projeto Rio Araguari-CPRM), visando à geração de produtos para o mapeamento geológico e exploração mineral da porção centro-sul do estado do Amapá. Essa região se reveste de especial importância visto que se trata de uma das últimas fronteiras exploratórias do país, onde são reconhecidos terrenos do embasamento Arqueano, seqüências do tipo greenstone-belts (Província Vila Nova) e suítes intrusivas, coletivamente de evolução geológica complexa e com amplo potencial metalogenético. Com base no processamento dos dados aerogeofísicos, foram gerados mapas de domínios e lineamentos magnéticos e domínios gamaespectrométricos, a partir dos quais novas unidades litogeofísicas foram reconhecidas, assim como redefinida, com grande precisão, a extensão de unidades previamente mapeadas (e.g., corpos enderbíticos, complexos máficos ultramáficos e intrusivas graníticas). As estruturas magnéticas são multi-orientadas. O extenso lineamento denominado Cupixi Alto Jarí aparece com destaque nos mapas aerogeofísicos, separando o Terreno Cinturão Jari e o Terreno Antigo CupixiTartarugal Grande. As estruturas de direção NNW são predominantes e se associam, com maior freqüência, às mineralizações auríferas da região.
\end{abstract}

Palavras-chave: aerogeofísica, greenstone belts, mapeamento geológico, mineralizações auríferas, Amapá.

\begin{abstract}
Geologic-geophysical mapping of the central portion of the Amapa state through processing and interpretation of airborne potential field data. This article approaches the processing and interpretation of high spatial resolution airborne geophysical data (magnetometry and gama-spectrometry) (Projeto Rio Araguari-CPRM), aiming to produce products for geologic mapping and mineral exploration of the central portion of the Amapa State, Brazil. This region is of special interest since it comprises one of the last exploration frontiers in Brazil, where Archaean basements units, greenstone belts (Vila Nova Province) and intrusive rocks collectively show a complex geologic evolution and an ample metallogenic potential.

The processing of the geophysical data yielded maps of magnetic lineaments and magnetic and gammaspectrometric domains, from which new litho-geophysical units were recognized and previously mapped units were redefined (e.g., enderbitic bodies, mafic-ultramafic complexes and granitic intrusives). The magnetic structures are multi-oriented. The extensive Alto Cupixi Jari lineament shows prominently in the magnetic maps, separating the Cinturao Jari and the Atingo-Cupixi-Tartarugal Grande terranes. The NNW-trending structures appear ubiquitously in these maps and are often associated to gold mineralizations in the region.
\end{abstract}

Keywords: airborne geophysics, greenstone belts, geologic mapping, gold mineralizations, Amapa-Brazil

INTRODUÇÃO A utilização de métodos indiretos no mapeamento geológico tem se tornado uma prática comum no Brasil (Blum 1999, Silva 1999, Teixeira 2003, Silva 2003), principalmente em regiões com dificuldades de acesso e densa vegetação, como é o caso do estado do Amapá (Rosa-Costa et al. 2001). Nessas situações, mapas derivados do processamento e interpretação de dados aerogeofísicos podem contribuir para a delimitação de unidades litológicas e estruturas, incluindo informações sobre sua profundidade e geometria.

Avanços recentes nas técnicas de processamento e integração de dados aerogeofísicos têm possibilitado a geração de mapas litogeofísicos aprimorados, os quais proporcionam uma melhor compreensão das relações de contato entre unidades geológicas, normalmente mascaradas devido à extensa cobertura laterítica e florestal, típicas da região Amazônica. Outro ponto importante é o reconhecimento, através desses dados, de zonas potencialmente hospedeiras de mineralizações que apresentam características geofísicas diferenciadas.

Considerando seu potencial em mapeamento geológico e exploração mineral, este artigo aborda o processamento e a interpretação de dados aerogeofísicos de alta resolução espacial e densidade de amostragem, visando a geração de produtos para o mapeamento geológico e exploração mineral da porção centro-sul do estado do Amapá na escala 1:100.000, onde a cartografia atual encontra-se disponível somente na escala 
1:1.000.000 (Projeto Carta Geológica do Brasil ao Milionésimo - SIG 1: 1.000 .000 - CPRM).

Os dados utilizados neste trabalho fazem parte do Projeto Aerogeofísico Rio Araguari realizado pela CPRM e Ministério de Minas e Energia no ano de 2004. Os dados foram processados, interpretados e integrados no intuito de se gerar uma base de dados que permita delinear o arcabouço regional e domínios/estruturas associados à mineralizações auríferas já reconhecidas nessa região.

A área de estudo está localizada na porção centro-sul do Amapá, a oeste da capital Macapá, englobando as cidades de Serra do Navio e Pedra Branca de Amapari, entre os meridianos $-51^{\circ} 26^{\prime}$ e $-52^{\circ} 35^{\prime}$ e os paralelos $1^{\circ} 23^{\prime}$ e $0^{\circ} 13^{\prime} \mathrm{N}$, e é recoberta em toda a sua extensão pelo Projeto Aerogeofísico Rio Araguari (Fig.1).

\section{GEOLOGIA REGIONAL}

Contexto geológico A área de estudo está inserida na província geocronológica Maroni-Itacaiúnas e é composta por rochas metavulcânicas e metassedimentares, deformadas e metamorfisadas na fácies xisto verde a anfibolito, compreendendo um terreno greenstone belt, além de rochas granulíticas e terrenos gnaisse-migmatitos, com remanescentes de crosta arqueana retrabalhada. Esta Província foi acrescionada à Província Amazônia Central durante um orógeno colisional que correspondeu ao período de maior formação de crosta (2.2 - $1.95 \mathrm{Ga})$ (Cordani et al. 1979).

O embasamento arqueano da região é composto por granulitos, gnaisses, anfibolitos e migmatitos do Complexo Guianense, que correspondem a rochas polimetamorfisadas e parcialmente retrabalhadas durante a orogênese Transamazônica (Lima et al., 1974) (Fig. 2). As idades mais antigas registradas nesse núcleo arqueano no Estado do Amapá giram em torno de 3,0 Ga (Avelar et al., 2001). No centro-leste do Amapá, rochas granulíticas apresentam idades em torno de $3.24-2.87$ Ga. Nessa mesma região, os corpos plutônicos Piriclasito Mutum e Enderbito Cobra, de magmatismo ácido e básico, respectivamente, são mais jovens, com idades de 2.87 e $2.64 \mathrm{Ga}$. Dois intervalos de metamorfismo foram determinados com base em idades $\mathrm{Pb} / \mathrm{Pb}$ obtidas em zircão: $2.65-2.53 \mathrm{Ga}$ e 2.10 a $1.90 \mathrm{Ga}$, que correspondem ao metamorfismo de alto grau no setor oriental do Escudo das Guianas (Faraco et al., 2001).

Intrudindo o embasamento arqueano ocorrem rochas máficas-ultramáficas do Complexo Máfico Ultramáfico Bacuri (CMUB) (Fig. 2). Este apresenta uma orientação geral E-W, sendo composto por rochas deformadas e metamorfisadas na fácies anfibolito alto, incluindo anfibolitos, serpentinitos, tremolititos e cromititos (Spier \& Ferreira Filho 1999). O CMUB hospeda importantes depósitos de cromita, sendo a segunda maior reserva brasileira de cromo (Spier \& Ferreira Filho 2001).

As rochas supracrustais na região central do Amapá são representadas por unidades da Província
Vila Nova, considerada como um terreno greenstone belt que ocorre em faixas alongadas de direção NW-SE (Fig. 2), metamorfisadas na fácies xisto-verde a anfibolito e deformadas em um domínio dúctil-rúptil, onde se desenvolveram extensas zonas de cisalhamento. A idade proposta para esta seqüência greenstone é paleoproterozóica, em torno de $2.26 \pm 0,34 \mathrm{Ga}$ (McReath \& Faraco, 1997) e metamorfismo em torno de $1,97 \pm 0.51$ Ga (Tassinari et al., 1984). Análises de rocha total em granadas de anfibolitos basais desta Província forneceram idades de $2.08 \pm 0.02$, indicando um metarmofismo que coincide com o magmatismo tardi-orogênico na Província Maroni Itacaiúnas (Pimentel et al., 2002).

As rochas intrusivas denominadas de Granodiorito Falsino $(1.75 \mathrm{Ga})$ e Alcalinas Mapari $(1.68-1.34$ Ga) (Lima et al., 1974) estão relacionadas a um evento Proterozóico regional, caracterizado por um magmatismo anorogênico intraplaca, com evidências de falhas de direção NE-SW e retrabalhamento, atribuídos ao Evento Jari-Falsino (1.2 Ga) (Dardenne \& Schobbenhaus, 2003). Estas falhas podem estar relacionadas à reativação de estruturas antigas, favorecendo a concentração de sulfetos mineralizados, além de gerarem um metamorfismo de contato e alterações hidrotermais nas rochas da seqüência metavulcano-sedimentar (Dardenne \& Schobbenhaus, 2001a).

Vasquez \& Lafon (2000), descrevem um magmatismo tipo $\mathrm{A}$ de $1.75 \mathrm{Ga}(\mathrm{Pb} / \mathrm{Pb})$ na porção oriental do Escudo das Guianas e sugerem que as Alcalinas Mapari estejam relacionadas a este evento cratogênico de $1.75 \mathrm{Ga}$.

Durante o Permo-Triássico, com a abertura do Oceano Altântico, a Província Maroni-Itacaiúnas foi afetada por um enxame de diques de diabásio, compreendidos na Suite Intrusiva Cassiporé, de idade entre $254-207 \mathrm{Ma}$.

Compartimentação tectônica Ricci et al. (2001) e Rosa Costa et al. (2001), descrevem a existência de diferentes terrenos geológico-geofísicos entre os estados do Pará e Amapá (Fig. 3), diferenciados pelos embasamentos geocronologicamente distintos e justapostos por megaestruturas tectônicas e/ou magnéticas, paralelas e de orientação NW-SE. Estes lineamentos são denominados de Cupixi - Alto Jari (LCAJ), a nordeste, e Ipitinga - Aldeia Bona (LIAB), a sudoeste, de cinemática sinistral e dextral, respectivamente.

Entre esses lineamentos, ocorre uma faixa de alto grau, denominada de Cinturão Jari (CJ), composta por ortognaisses de fácies anfibolito a granulito, terrenos greenstone belts e rochas metassedimentares granulitizadas e retrometamorfisadas na fácies xisto-verde. A sudoeste do LIAB localiza-se o Orógeno CarecuruParu (OCP), composto por granitóides de composição granítica a tonalítica e ortognaisses, terrenos greenstone belt metamorfizados na fácies xisto-verde, além de um núcleo granulítico arqueano. A nordeste do LACJ encontra-se o terreno Antigo Cupixi - Tartarugal Grande (TACTG), composto por ortognaisses de fácies anfibolito, granulitos e por seqüências supracrustais tipo 


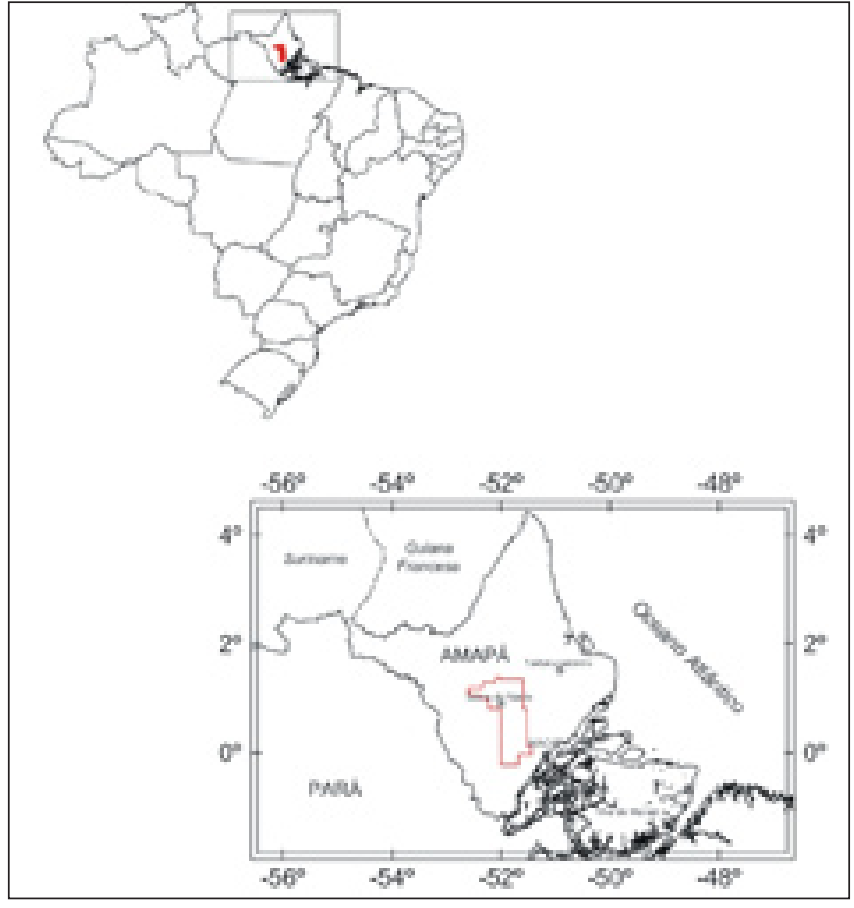

Figura 1 - Mapa de localização da área de estudo.

greenstone belt da Província Vila Nova (Fig. 3). Segundo Rosa-Costa et al. (2003), o CJ representa o domínio mais deformado em relação aos adjacentes, com um grande número de lineamentos magnéticos que representam, principalmente, zonas de cisalhamento transcorrentes. Datações indicam idades dominantemente arqueanas para o CJ $(2.652 \pm 4 \mathrm{Ma} \mathrm{e} \geq 2.80 \mathrm{Ga})$, para o TACTG $(2.85 \mathrm{Ga}$ e $\geq 2.85 \mathrm{Ga})$ e para o NGP $(2.597 \pm 4$ Ma) e, dominantemente paleoproterozóicas para o OCP $(2.150 \pm 1 \mathrm{Ma})$.

Mineralizações auríferas Os depósitos de ouro da região central do Amapá estão associados às seqüências vulcano-sedimentares Paleoproterozóicas (quartzitos, pelitos e formações ferríferas bandadas), da Província Vila Nova, e granitóides. Entre os principais, podem-se citar os depósitos de ouro (i) Ipitinga e Amapari, hospedados em formações ferríferas bandadas; (ii) Salamangone, hospedado em granitóides calcio-alcalinos; (iii) Santa Maria e Vicente, hospedados em rochas metassedimentares clásticas. Esses depósitos são, em geral, classificados como orogênicos do tipo lode. A mineralização ocorre em zonas metamórficas, controladas pela foliação regional, em zonas de cisalhamento e falhas reversas oblíquas, de direções N50-60E e N30W. Na área de estudo ocorrem mineralizações associadas aos depósitos de Santa Maria, Vicente e Amapari.

NATUREZA DOS DADOS ESTUDADOS Os dados utilizados neste trabalho fazem parte da Base de Dados de Projetos Aerogeofísicos do Brasil - AERO, criado em 1995 pelo Serviço Geológico do Brasil CPRM. Este banco de dados é organizado em séries numeradas de acordo com o ano do levantamento. Para este projeto utilizou-se a série 1000, código 1065 - Projeto Rio Araguari.

O levantamento na área de estudo foi realizado entre os meses de setembro e outubro/2004 e teve como características do levantamento (a) Intervalo de amostragem de $0.1 \mathrm{~s} ; 7.8 \mathrm{~m}$ (magnetometria) e 1,0s; $78 \mathrm{~m}$ (gamaespectrometria); (b) Altura do vôo de $100 \mathrm{~m}$; (c) Linhas de vôo na direção $N 45^{\circ} \mathrm{E}$ e espaçamento de $500 \mathrm{~m}$; (d)Linhas de controle na direção $\mathrm{N} 45^{\circ} \mathrm{W}$ e espaçamento de $10.000 \mathrm{~m}$; (e) Área total: $10.872 \mathrm{~km}^{2}$ e (f) Aeronave: Cessna, modelo 404 Titan, prefixo PT-FZN equipada com magnetômetro de bombeamento ótico de vapor de césio da SCINTREX, modelo CS-2 e com gamaespectrômetro da EXPLORANIUM, modelo GR820 , de 256 canais espectrais e sistema de navegação GPS, com receptor SERCEL de 12 canais.

PROCESSAMENTO DOS DADOS O software utilizado no processamento dos dados aerogeofísicos foi o GEOSOFT Inc. OASIS Montaj TM. A figura 3 apresenta um sumário das etapas de processamento dos dados magnetométricos. Tais dados foram analisados segundo a sua distribuição espacial, densidade e a presença de valores altamente anômalos, quando comparado com os demais pontos fiduciais vizinhos.

Os dados em perfil do campo magnético anômalo foram verificados quanto à presença de dados espúrios, através dos testes de consistência de Diferença Quarta e Parâmetro P (Blum 1999). A diferença quarta consiste em derivar os dados quatro vezes sucessivamente, de forma que o resultado destas derivações contenha somente informações de mais alta freqüência, geralmente relacionada aos ruídos. O teste do parâmetro P leva em consideração que $99.7 \%$ dos dados giram em torno de uma média entre -3 e +3 vezes o desvio padrão dos dados coletados. Desta forma, o método permite isolar os "picos" nos perfis, que representam os ruídos (Blum 1999). A aplicação desses testes aos dados magnetométricos mostrou a inexistência de ruídos, em padrões e quantidade, que eventualmente possam comprometer os resultados pretendidos nas etapas de processamento e interpretação dos dados.

A maioria das técnicas de processamento 2D necessita de que os dados estejam distribuídos em uma malha regular. Para tanto, os dados magnetométricos e gamaespectrométricos foram interpolados segundo dois métodos: curvatura mínima e bidirecional, para avaliação de qual método apresenta o melhor resultado para cada conjunto de dados.

O método da curvatura mínima gera uma superfície suavizada com os valores o mais próximo possível dos dados originais, sendo muitas vezes utilizado pela rapidez no processamento e eficiência dos resultados (Parro, 1998). O método bidirecional é indicado para interpolar dados cujo levantamento dos dados seja feito em linhas aproximadamente paralelas, pois tendem a realçar as feições perpendiculares às linhas do levantamento (Parro, 1998).

Foram testadas interpolações com diferentes 


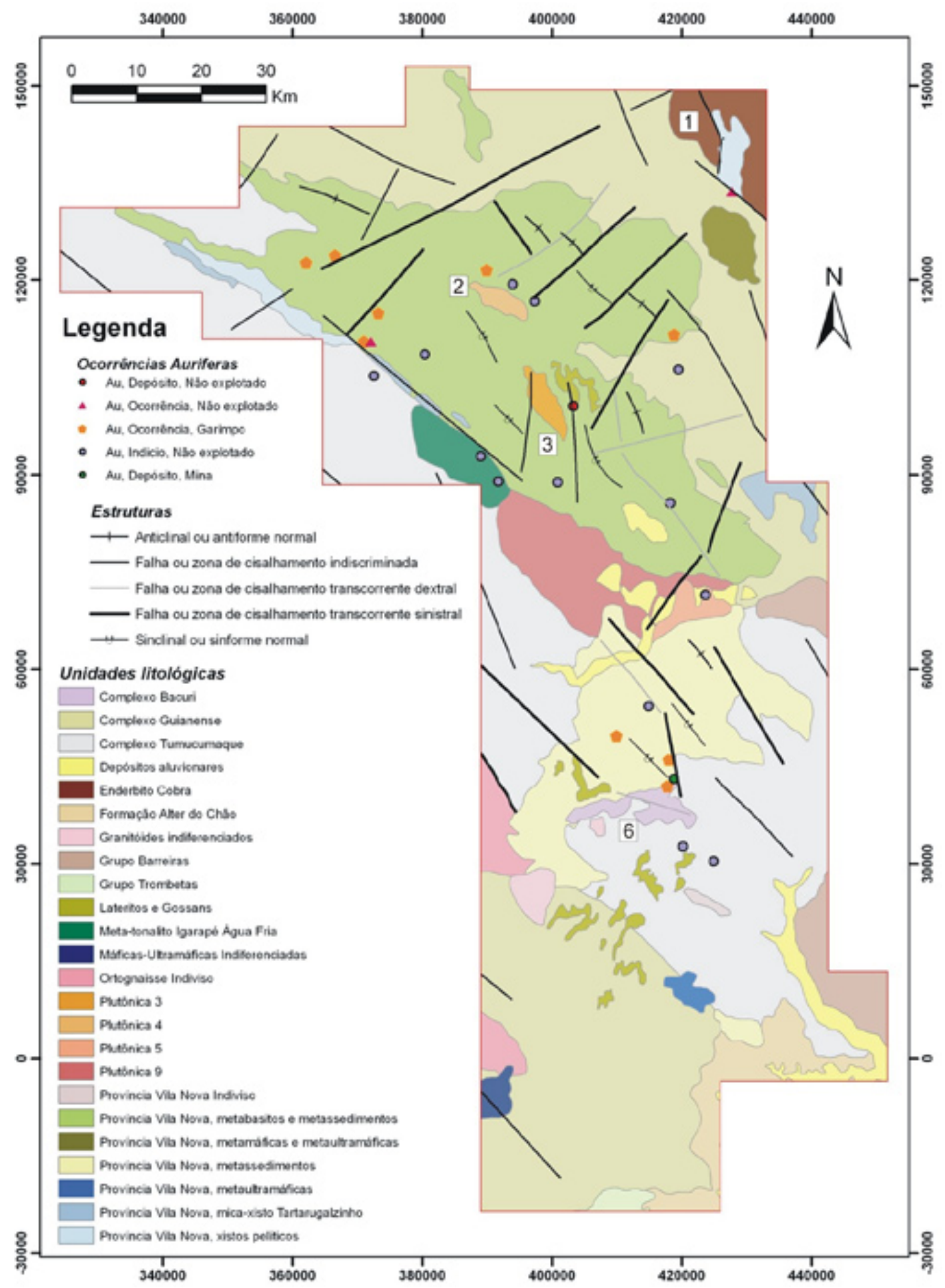

Figura 2 - Mapa geológico da área do projeto, na escala 1:1.000.000 (Bahia et al. 2004, Faraco et al. 2004), destacando as unidades: 1-Enderbito Cobra; 2-Plutônicas 4; 3-Plutônicas 3; 6-Complexo Bacuri. Neste mapa também são plotadas as ocorrências auriferas da base de dados da CPRM.

números de interações $(100,500,1000$ e 5000) e tamanhos de célula da malha $(125 \mathrm{~m}$ e $250 \mathrm{~m})$, para ambos os métodos. Os resultados obtidos foram comparados segundo o número de interações, o tamanho da célula da malha e também quanto à aproximação dos dados interpolados em relação aos valores originais.

Os produtos gerados a partir do campo magné- tico anômalo foram obtidos a partir dos dados interpolados pelo método bidirecional, com tamanho da célula da malha de $125 \mathrm{~m}$. Essa especificação foi a que resultou no maior detalhamento das anomalias magnéticas, em contraste com um baixo nível de ruídos.

Os produtos gerados com base nos dados gamaespectrométricos foram obtidos a partir dos dados 


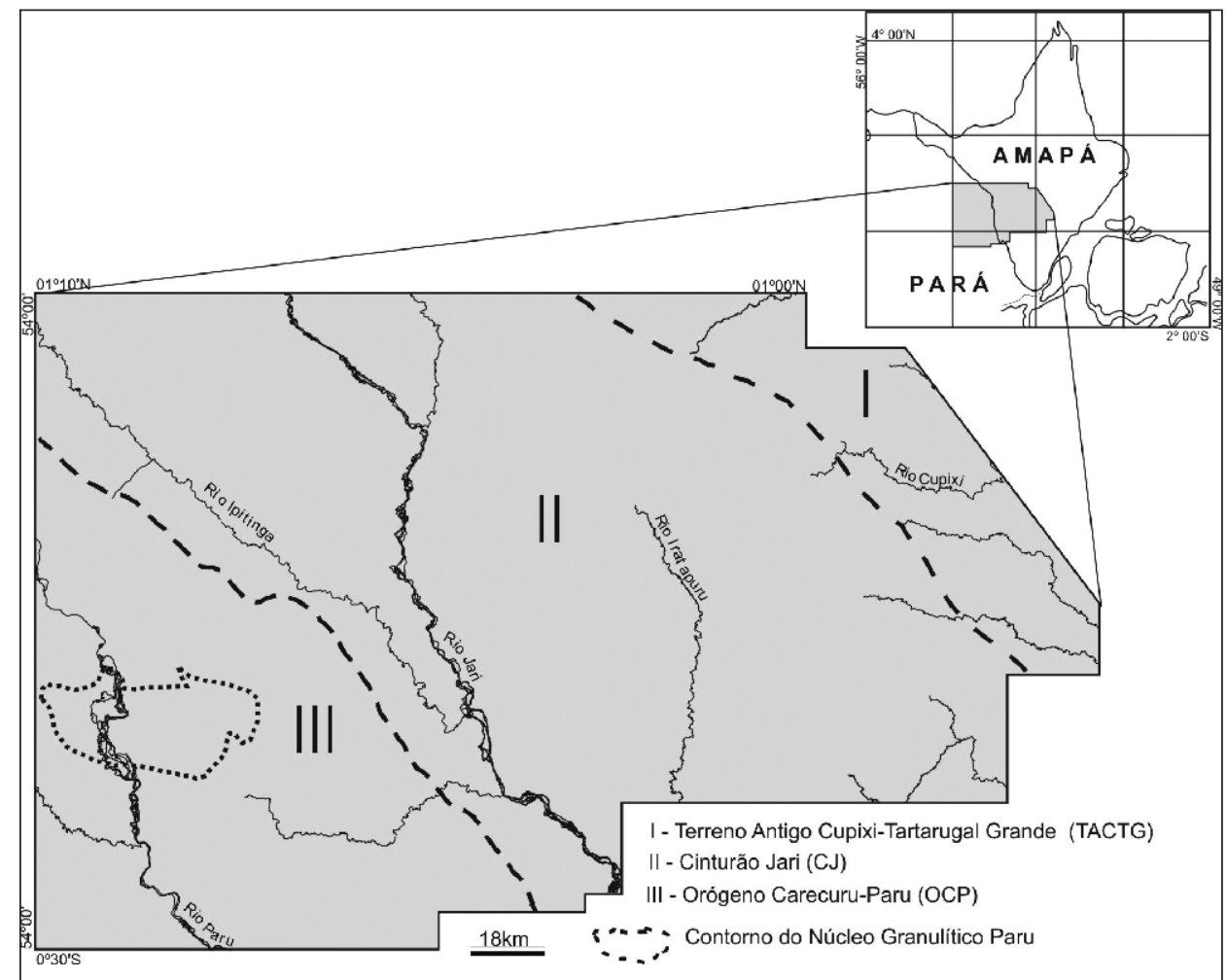

Figura 3 - Mapa do Projeto RENCA onde foi definido a compartimentação dos domínios tectônicos (Modificado de Rosa Costa et al., 2003).

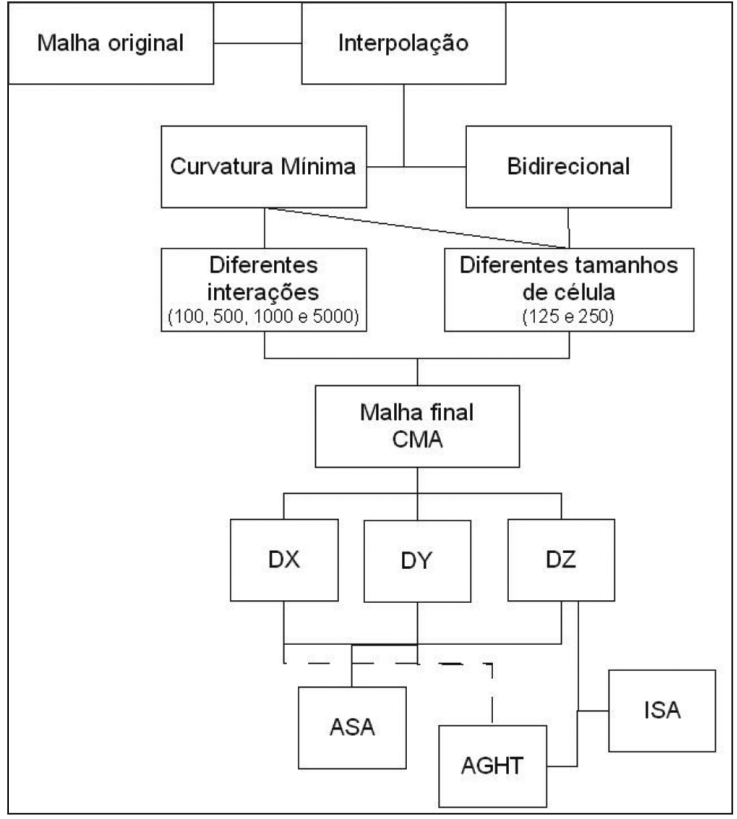

Figura 4 - Fluxograma de operações ilustrando o processamento dos dados magnetométricos e as transformações lineares no domínio do espaço. CMA (campo magnético anômalo), ASA (amplitude do sinal analítico), DZ, DX e $D Y$ (derivadas vertical e horizontais), AGHT (amplitude do gradiente horizontal total) e ISA (inclinação do sinal analítico). interpolados pelo método da curvatura mínima, com tamanho da célula da malha de $125 \mathrm{~m}$ e 100 interações. Esse resultado, quando comparado aquele derivado pelo método bidirecional, mostrou-se superior.

\section{GERACÃO E REALCE DOS PRODUTOS DERI- VADOS DE DADOS AEROMAGNÉTICOS E AE- ROGAMAESPECTROMÉTRICOS \\ Dados magnetrométricos Os produtos gerados a} partir dos dados magnéticos foram obtidos segundo as etapas ilustradas na figura 4. Esses produtos foram utilizados na confecção do mapa de lineamentos magnéticos e no mapa de domínios magnéticos, tendo como base, principalmente, a imagem da amplitude e da inclinação do sinal analítico (ASA e ISA, respectivamente).

A amplitude do sinal analítico (ASA) consiste numa técnica eficiente para a determinação de parâmetros geométricos, como localização de limites geológico e estruturais e profundidade de corpos (Blum, 1999). Representa uma função simétrica cujos picos são centrados nas bordas do corpo anômalo ou na feição geológica correspondente ( Milligan \& Gunn, 1997). A partir desta imagem foi possível gerar um mapa de domínios magnéticos, através de processos automáticos de classificação não-supervisionada, e posterior delimitação dos domínios a partir da análise e interpretação visual. O mapa final foi classificado em cinco domínios magnéticos: muito alto, alto, médio, baixo e muito baixo, de acordo com a intensidade do campo magnético anômalo (Figs. 5 e 6). $O$ mapa de amplitude do sinal analítico foi também classificado quantitativamente pelo 


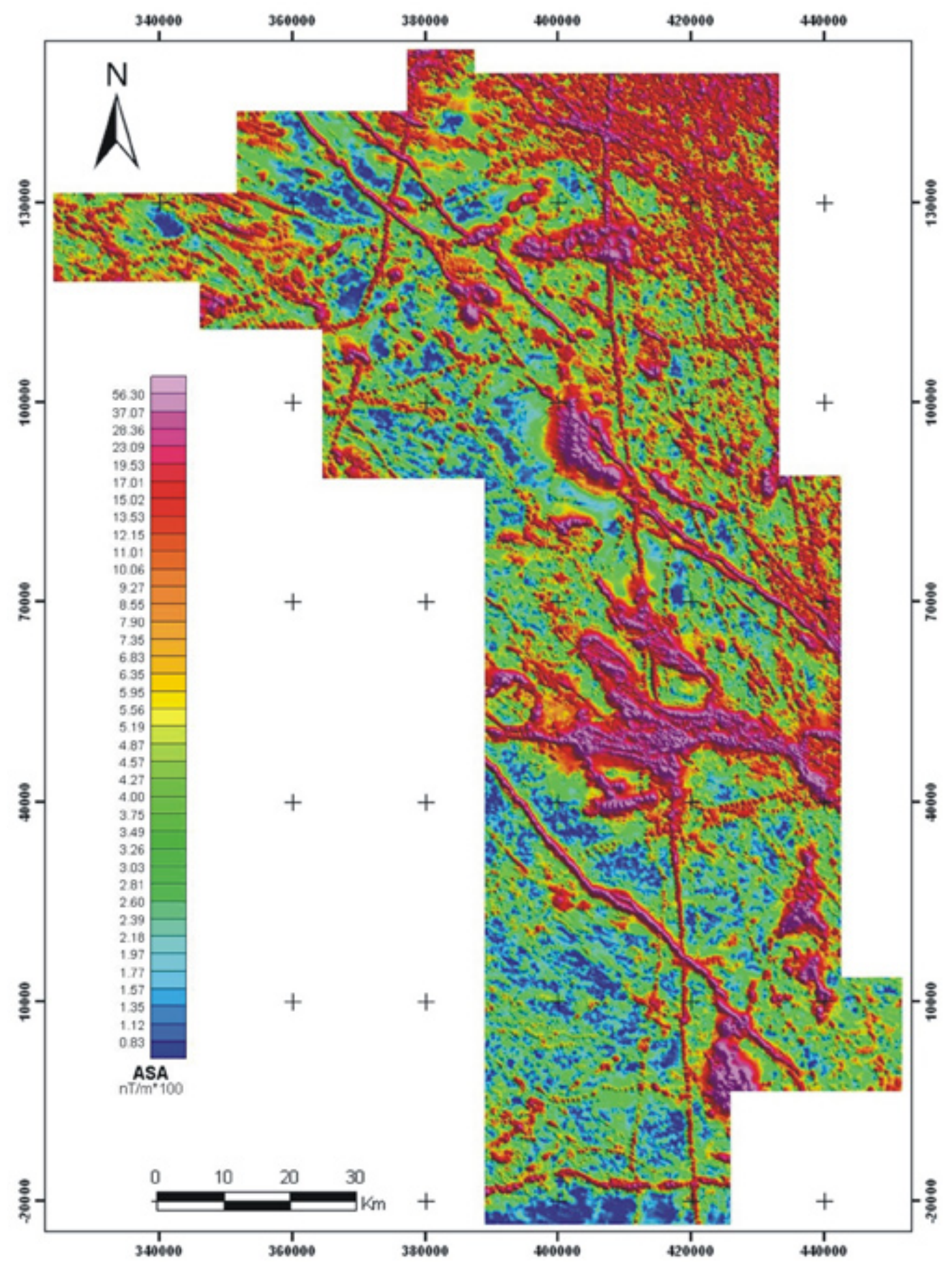

Figura 5 - Imagem da amplitude do sinal analítico de ordem 0, gerada pelo método bidirecional, com tamanho da célula da malha de $125 \mathrm{~m}$ e com 100 interações.

método de quebras naturais segundo as mesmas cinco classes derivadas visualmente em: muito alto $(0,93$ $-19,8 \mathrm{nT} / \mathrm{m})$, alto $(0,16-0,93 \mathrm{nT} / \mathrm{m})$, médio $(0,05-$ $0,16 \mathrm{nT} / \mathrm{m})$, baixo $(0,007-0,05 \mathrm{nT} / \mathrm{m})$ e muito baixo $(0,0003-0,007 \mathrm{nT} / \mathrm{m})$.

A imagem da inclinação do sinal analítico (ISA) permite a estimativa do mergulho da fonte causativa e, consequentemente, o contraste local de susceptibilidade. Sua textura relativa permite delimitar as diversas unidades magnéticas e feições pouco aparen- tes na amplitude do sinal analítico. Assim, é eficiente no mapeamento de feições lineares do relevo magnético (Thurston \& Smith, 1997). Nesse produto, as fontes magnéticas são representadas numa mesma superfície, permitindo, desta forma, o traçado de estruturas lineares, que geralmente representam fraturas e falhas geológicas (Figs. 7 e 8).

Dados gamaespectrométricos A partir da interpolação dos dados originais, foram geradas as imagens dos 


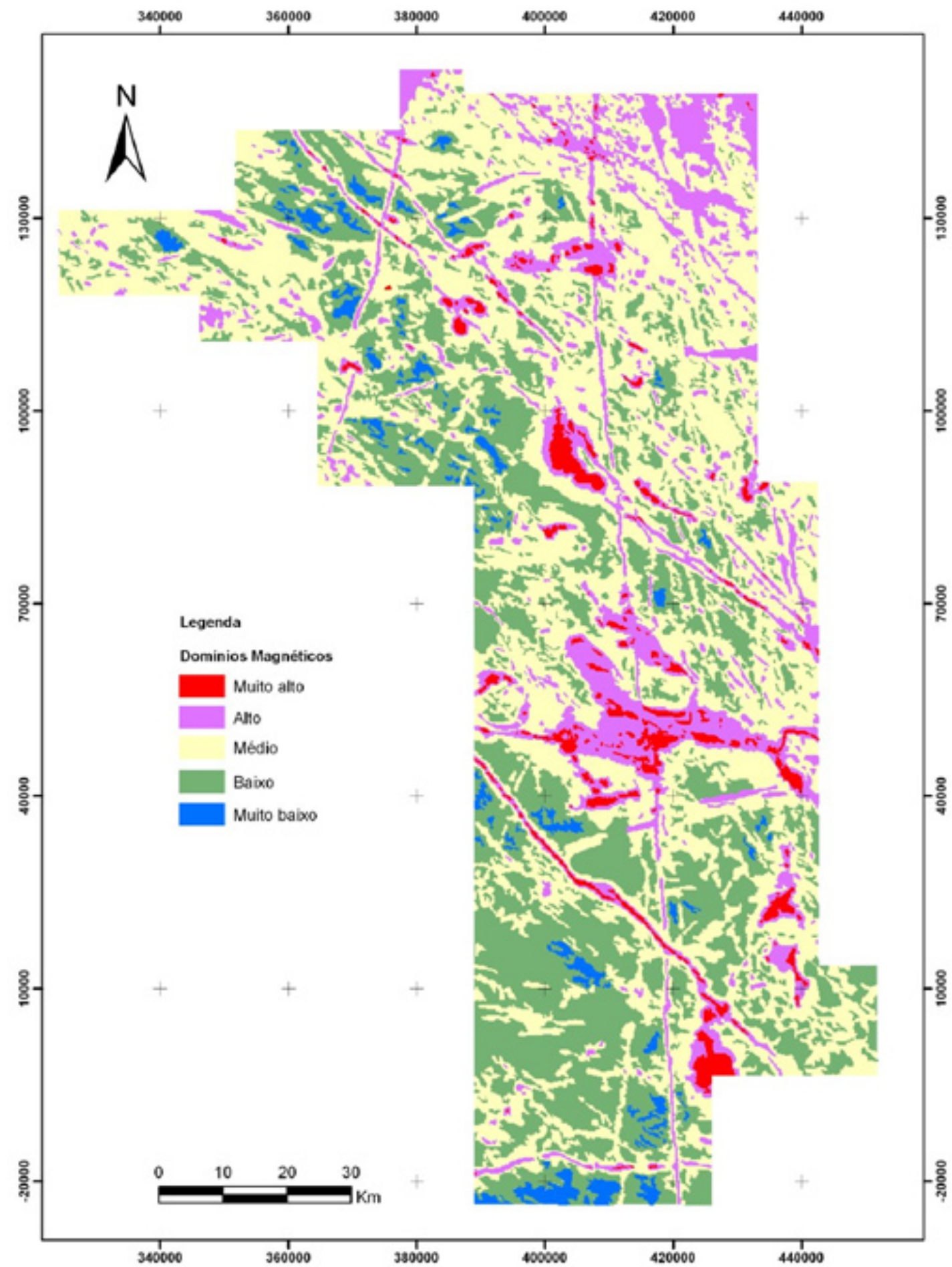

Figura 6 - Mapa de domínios magnéticos confeccionado com base na imagem da amplitude do sinal analítico de ordem 0 e do mapa de amplitude do gradiente horizontal total. (imagem colorida disponível na versão on-line)

canais do potássio, tório e urânio e confeccionadas as composições ternárias RGB e CMY, segundo as etapas apresentadas no fluxograma da figura 9.

Com base nessas imagens foi possível gerar um mapa de domínios gamaespectrométricos que envolveu a análise visual dos mapas dos canais individuais do potássio, tório e urânio, da composição K,Th,U (RGB), K,U,Th (RGB), K, Th, U (CMY), K, U, Th (CMY), além da imagem de contagem total. Imagens de radar do sensor JERS-1-SAR e dados altimétricos derivados do Shuttle Radar Topographic Mission (SRTM) também foram utilizados complementarmente na definição dos limites de alguns domínios, com base na textura e na altitude do terreno (Fig. 10). Nesse mapa, cada domínio representa uma combinação da variação dos radioelementos $\mathrm{K}$, eTh e eU, classificados pela combinação de valores 


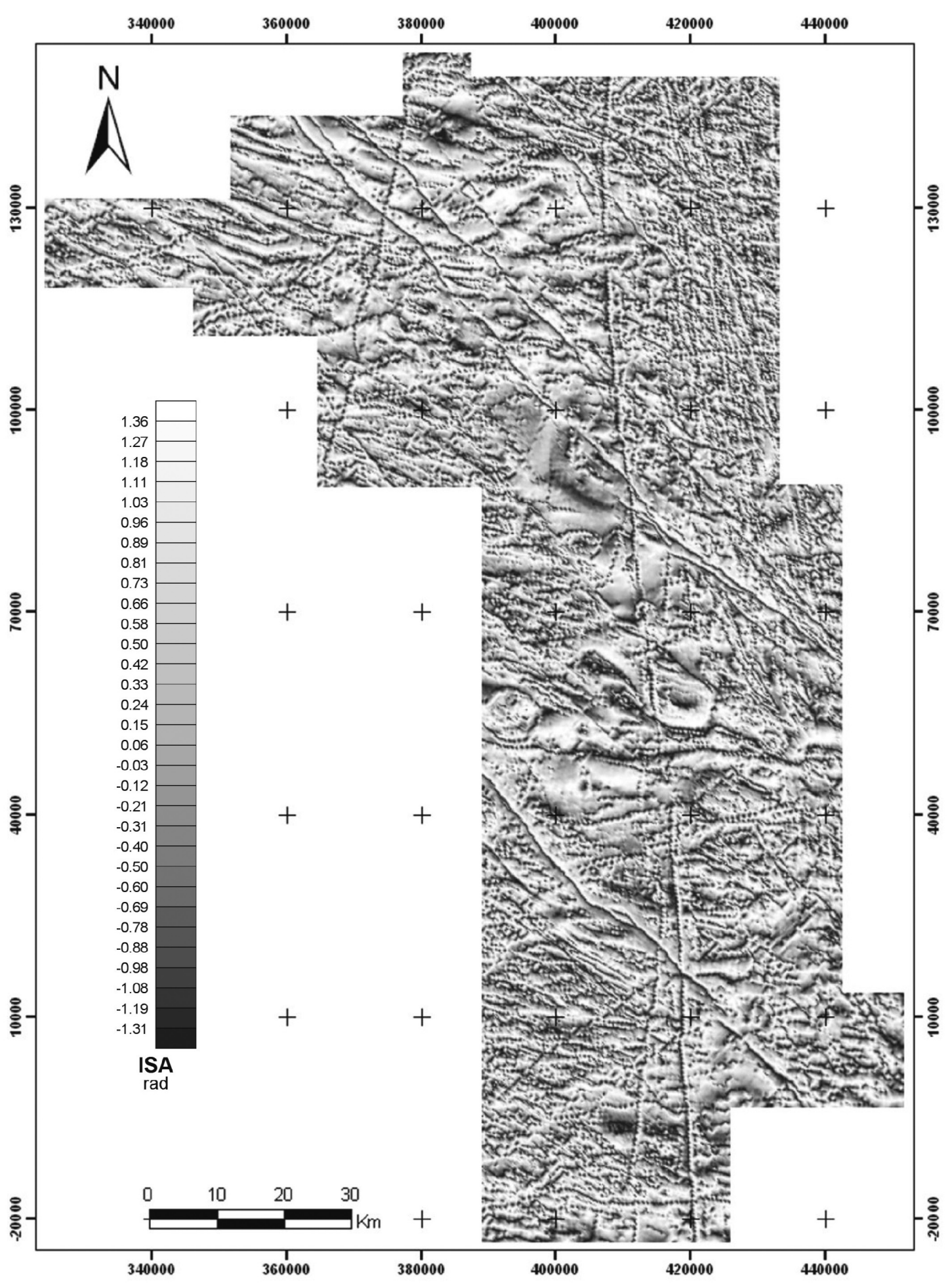

Figura 7 - Imagem da inclinação do sinal analítico gerada a partir do campo magnético anômalo interpolado pelo método bidirecional, com tamanho da célula da malha de $125 \mathrm{~m}$, com 100 interações.

alto, médio e baixo para cada elemento (Fig. 11).

Os mapas dos canais de CT, K, eTh e eU foram também classificados pelo método de quebras naturais com 10 classes, possibilitando a atribuição de valores de concentração para cada classe nos mapas individuais. Esta etapa permitiu uma reorganização em 33 classes (inicialmente individualizadas em 38), conforme a tabela 1.

\section{DISCUSSÕES}

Correlações com a geologia regional $\mathrm{O}$ realce dos dados aerogeofísicos permitiu observar uma diversidade litológica até então não registrada e cartografada na área de estudo. A imagem de composição ternária (Fig. 10) mostra uma maior variação dos radioelementos $K$, eTh e eU na porção centro-norte da área, sendo que ao sul o comportamento é mais homogêneo. O mapa de 


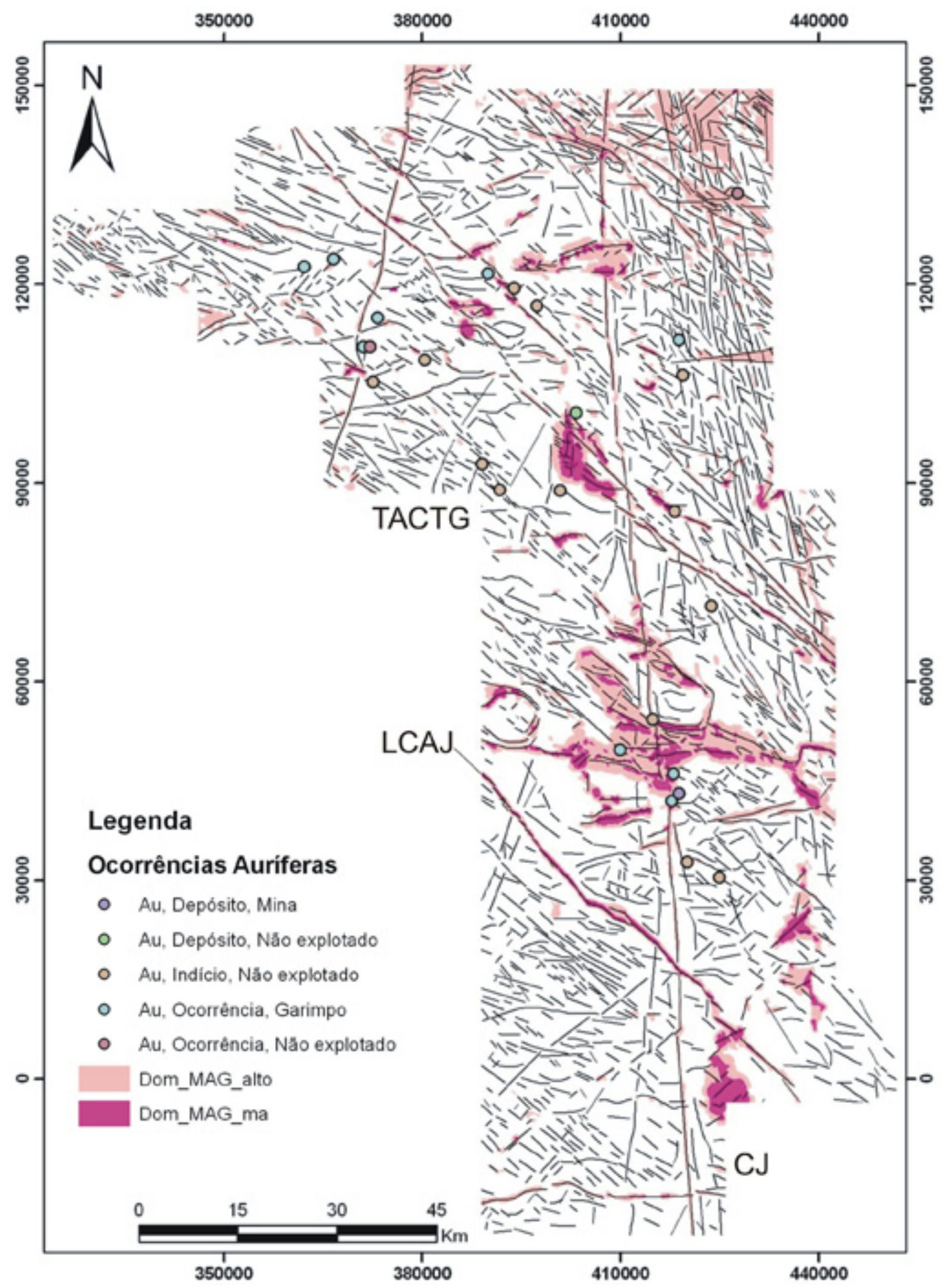

Figura 8 - Mapa de lineamentos magnéticos confeccionado com base nas derivadas horizontais, vertical, e na inclinação do sinal analítico. CJ-Cinturão Jari, LCAJ-Lineamento Cupixi - Alto Jari, TACTG- Terreno Antigo Cupixi Tartarugal Grande. As mineralizações auriferas documentadas na região encontram-se plotadas nesse mapa.

domínios gamaespectrométricos (Fig. 11) ilustra esta variedade, principalmente nos domínios da Província Vila Nova, na porção central da área, onde há um maior número de domínios delimitados (Fig. 2).

Algumas unidades previamente mapeadas apresentaram correlação com o mapa gamaespectométrico, como, por exemplo, o Enderbito Cobra (Ponto 1 - Figs. 2 e 11). Porém, neste novo mapa, essa unidade abrange uma área mais restrita na direção sudeste. Dois corpos plutônicos (Pontos 2 e 3 - Figs. 2 e 11), datados de 2.109 e 2.128 Ma pelo método U-Pb (Faraco et al. 2004), também foram identificados com uma assinatura 


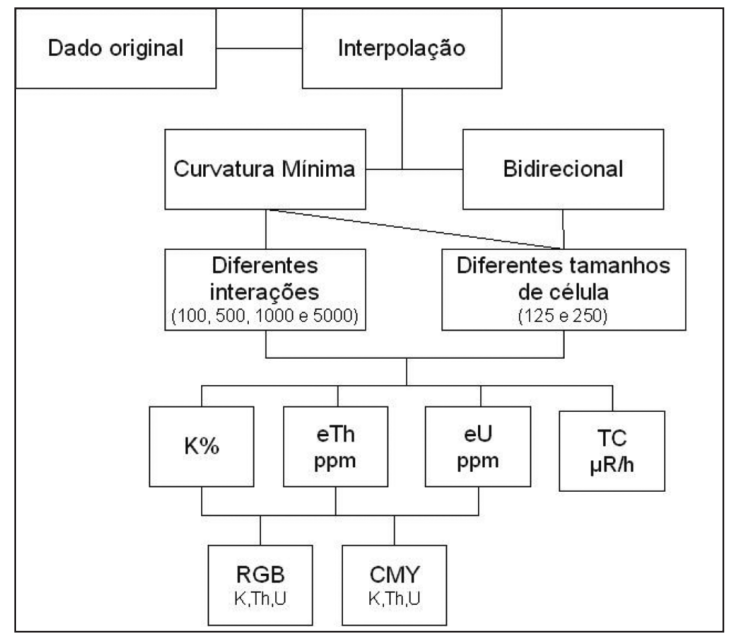

Figura 9 - Fluxograma ilustrando o processamento dos dados gamaespectrométricos e as etapas de geração dos produtos.

gamaespectométrica que abrange uma área de dimensões maiores. O corpo localizado mais ao norte (Ponto 2 - Fig. 11) apresenta uma diferenciação composicional das bordas para o centro. Apesar de suas idades serem muito próximas, estes dois corpos exibem assinatura radiométrica e orientação distintas: (i) o corpo do ponto 2 (Plutônica 4) tem K médio a alto, eTh alto, eU alto e $\mathrm{K}$ médio, eTh médio a alto, $\mathrm{U}$ médio e está alongado na direção NW; (ii) o corpo do ponto 3 (Plutônica 3; Granito Amapari), possui K alto, eTh alto, U alto e está alongado na direção NS (Ponto 3 - Fig. 11).

Também foi possível delimitar outros corpos intrusivos no terreno greenstone da Província Vila Nova e no Complexo Guianense, baseando-se principalmente na sua forma circular. O primeiro conjunto (Ponto 4 -
Fig. 11), intrudido nas rochas da Província Vila Nova, apresenta assinatura radiométrica de $\mathrm{K}$ médio, eTh médio, eU alto, enquanto o segundo (Ponto 5 - Fig. 11), intrusivo no embasamento, apresenta $\mathrm{K}$ médio, eTh médio a alto, eU alto. $\mathrm{O}$ comportamento radiométrico $\mathrm{e}$ a forma de ocorrência sugerem uma natureza semelhante para estas intrusões.

O Complexo Máfico-Ultramáfico Bacuri (Ponto 6 - Figs. 2 e 11), localizado na porção central da área e com orientação leste-oeste, apresenta um prolongamento para sul. A assinatura radiométrica deste complexo (K médio, eTh baixo, eU baixo) apresenta correspondentes ao norte da área, na forma de sigmóides de direção NW/SE (Ponto 6b - Fig. 11), que não foram identificados em mapas prévios.

O mapa de lineamentos magnéticos apresenta estruturas em diferentes direções: NW, NS, NE e EW, além de estruturas circulares associadas aos altos magnéticos. Os lineamentos de direção NW e NS ocorrem com maior freqüência na porção $\mathrm{NE}$ da área e formam um relevo magnético bem acidentado. As extensas zonas de cisalhamento mapeadas em projetos anteriores (Projeto Renca) aparecem ainda mais definidas nesses dados de maior resolução espacial, sendo possível compartimentar a área em três domínios em escala regional (Fig. 8).

O domínio localizado a sudoeste da área é marcado por um relevo magnético mais baixo, dominado por lineamentos de direção NW. Este domínio pode ser relacionado ao Cinturão Jari, sendo separado do domínio central por uma zona de cisalhamento de transcorrência sinistral dúctil, conhecida como Lineamento Cupixi - Alto Jari (LCAJ) (Fig. 8). É formado por rochas do Complexo Guianense, ortognaisses indivisos, máficas-ultramáficas indiferenciadas e coberturas sedimentares paleo-mesozóicas da Formação Altér do Chão

\begin{tabular}{c|c|c}
\hline \multirow{4}{*}{ K (\%) } & Médio a baixo & $<0,03$ a 0,1 \\
\cline { 2 - 3 } & Médio & $<0,03$ a 0,5 \\
\cline { 2 - 3 } & Médio a alto & 0,03 a 0,7 \\
\cline { 2 - 3 } & Alto & 0,03 a 0,9 com picos locais de 2,4 \\
\hline \multirow{4}{*}{ eTh $(\mathrm{ppm})$} & Muito alto & 0,2 a 0,9 \\
\cline { 2 - 3 } & Baixo & $<2,2$ a 9,2 \\
\cline { 2 - 3 } & Médio a baixo & 2,2 a 15,3 \\
\cline { 2 - 3 } & Médio & 2,2 a 26,4 \\
\cline { 2 - 3 } & Médio a alto & 2,2 a 32,8 \\
\hline & Alto & 6,2 a 62,8 \\
\hline \multirow{5}{*}{ eU (ppm) } & Muito alto & 15,3 a 62,8 \\
\cline { 2 - 3 } & Baixo & $<0,4$ a 2,3 \\
\cline { 2 - 3 } & Médio a baixo & 0,4 a 2,8 \\
\cline { 2 - 3 } & Médio & 0,4 a 4,2 \\
\cline { 2 - 3 } & Médio a alto & 0,4 a 5,8 \\
\hline & Alto & 0,4 a 13,6 \\
\hline
\end{tabular}

Tabela 1 - Tabela com os valores de concentração para cada radionuclídeo em relação aos domínios individualizados. 


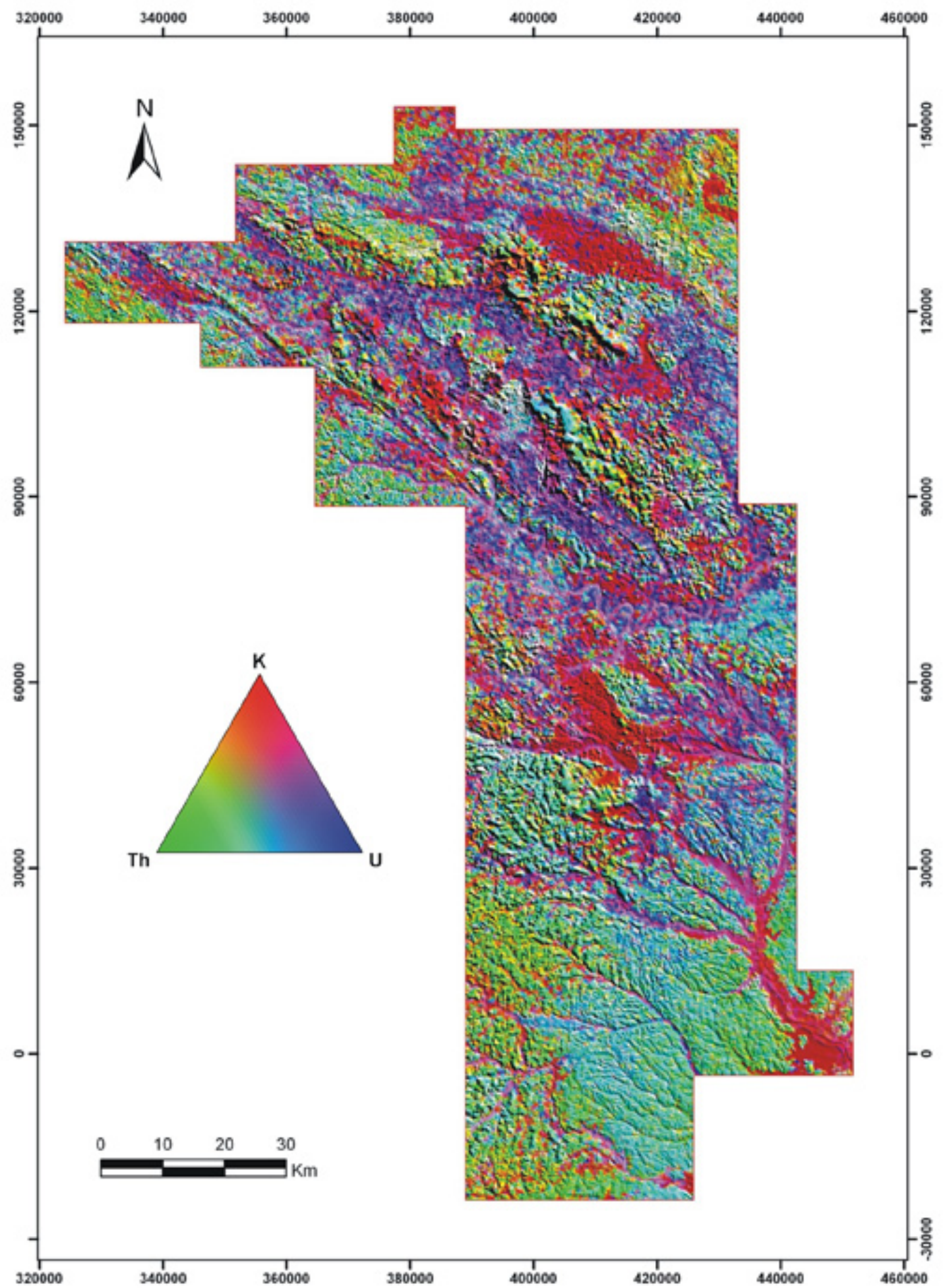

Figura 10 - Imagem de composição ternária $K T h U(R G B)$ sobreposta ao modelo digital de terreno (SRTM).

e Grupo Trombetas.

A nordeste do Cinturão Jari está localizado o Terreno Antigo Cupixi-Tartarugal Grande (TACTG), atribuído ao domínio central. Este domínio apresenta um relevo magnético intermediário, onde se concentram os maiores corpos magnéticos, possivelmente associados às formações ferríferas bandadas (BIF), que hospedam importantes mineralizações auríferas (ex. Depósito Amapari).

Neste domínio foi possível mapear duas uni- dades litogeofísicas com respostas magnéticas muito altas e que não apresentam correlação com o mapa geológico regional. Uma delas tem aproximadamente $54 \mathrm{~km}$ de extensão na direção leste-oeste e é marcada por um alto gradiente magnético e por alta concentração de potássio (Fig. 8; Ponto 7 - Fig. 11). No mapa geológico regional, essa unidade é descrita como um conjunto de rochas metassedimentares. Porém, em toda a área de estudo, tais rochas apresentam um comportamento característico e distinto do aqui observado, o que 


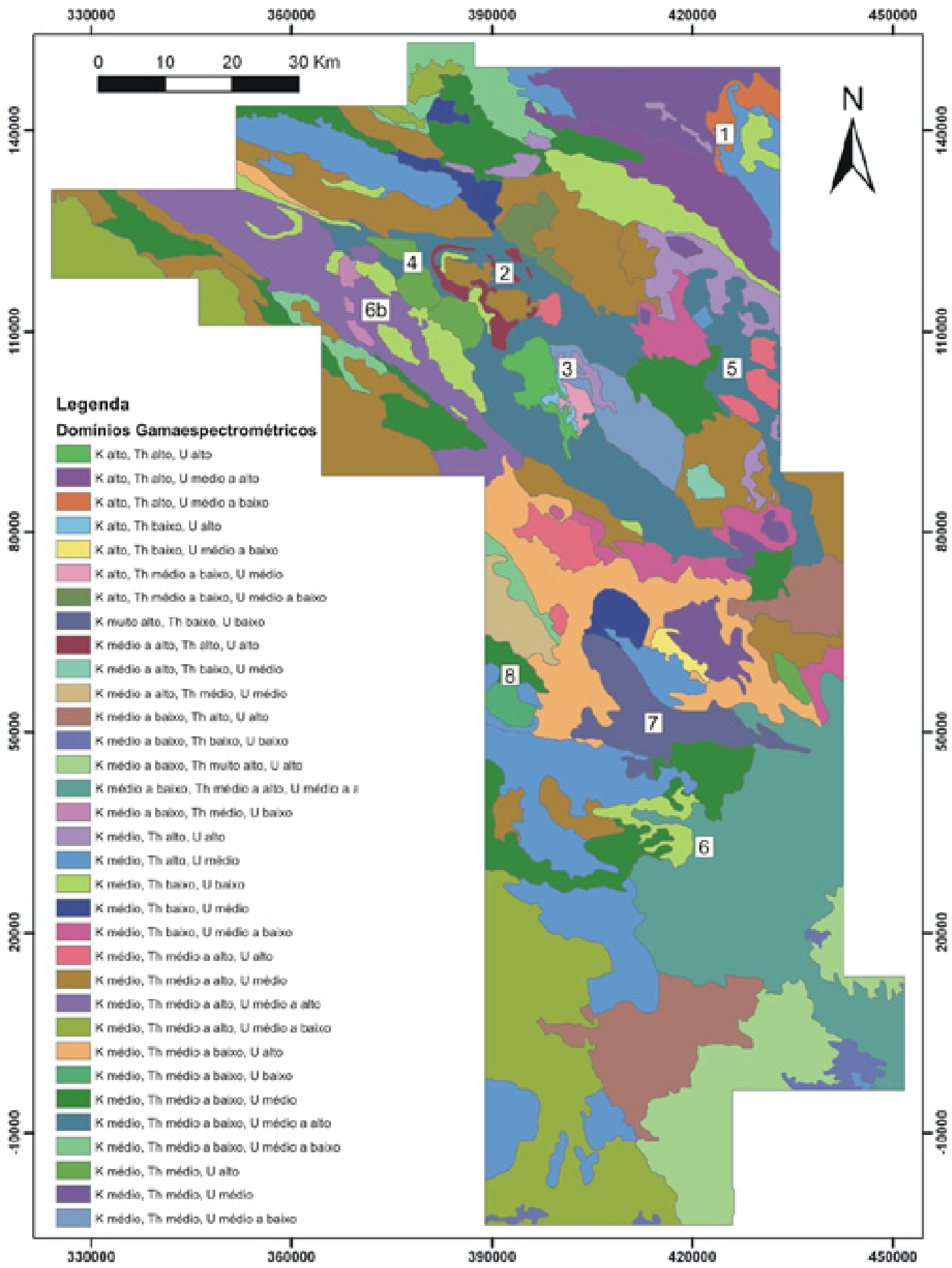

Figura 11 - Mapa de domínios gamaespectrométricos confeccionado a partir das imagens dos canais individuais do potássio, tório e urânio, composições RGB e CMY. 1-Enderbito Cobra; 2-Plutônica 4; 3-Plutônica 3; 4 e 5-Corpos plutônicos na ordem de citação no texto; 6-Complexo Bacuri. 7- Anomalia potássica-magnética.

sugere a existência de outra associação litológica, até então não reconhecida nesse setor. Outra feição antes não devidamente reportada, compreende um corpo de forma circular, com diâmetro de $10 \mathrm{~km}$, borda magnetizada e com uma variação da assinatura radiométrica das bordas para o centro (bordas apresentam K médio,
eTh alto, eU alto e o núcleo exibe $\mathrm{K}$ médio, eTh médio a baixo, eU baixo) (Fig. 8; Ponto 8 - Fig. 11).

O domínio central abrange as rochas do Complexo Tumucumaque, do Complexo Máfico-Ultramáfico de Bacuri, da Província Vila Nova, além de suítes plutônicas de idades distintas e coberturas sedimentares 
cenozóicas do Grupo Barreiras (Fig. 2).

Compartimentando o TACTG a nordeste, ocorre um domínio com relevo magnético acidentado e que contém rochas do Complexo Guianense, da Província Vila Nova e o Enderbito Cobra (Figs. 2 e 8). Neste domínio ocorrem, preferencialmente, estruturas de direção NNW.

A área é cortada no sentido norte-sul por extensos diques de direção NNE, que podem estar associados a diques básicos desenvolvidos durante a abertura do oceano Altântico (Lima 2006), e outros de menor extensão, de direção EW, localizados a sul e a noroeste (Fig. 8).

Assinaturas geofísicas e mineralizações de Au Os depósitos e ocorrências auríferas da área de estudo são classificados como orogenéticos do tipo lode, e ocorrem na forma de veios de quartzo sulfetados. O traçado dos lineamentos magnéticos permite uma melhor compreensão da distribuição desses depósitos e sua relação com estruturas tectônicas.

Os principais depósitos e ocorrências registrados na área ocorrem na porção centro-norte, no terreno TACTG, hospedados em rochas da Província Vila Nova, do embasamento arqueano e em rochas intrusivas da unidade Plutônica 5. As mineralizações de $\mathrm{Au}$ estão, na sua maioria, associadas a zonas de cisalhamento de direção NW e, subordinadamente, NNE (Fig. 8). No mapa de domínios magnéticos, as mineralizações ocorrem em três dos cinco domínios individualizados: onze ocorrências estão inscritas no domínio magnético médio, dez ocorrências no domínio baixo, e cinco no domínio magnético alto.

No mapa de domínios gamaespectrométricos, das 33 classes diferenciadas, 12 estão associadas às mineralizações (Tab. 2).

Tabela 2 - Freqüencia de ocorrências auriferas em relação às classes de domínios gamaespectrométricos.

\begin{tabular}{c|c}
\hline $\begin{array}{c}N^{\circ} \text { de } \\
\text { ocorrências } \\
\text { auríferas }\end{array}$ & Domínio Gamaespectrométrico \\
\hline 05 & K médio, eTh médio a baixo, eU médio a alto \\
\hline 05 & K médio, eTh médio a alto, eU médio a alto \\
\hline 02 & K médio, eTh baixo, eU médio a baixo \\
\hline 02 & K muito alto, eTh baixo, eU baixo \\
\hline 02 & K médio a baixo, eTh médio a alto, eU médio a alto \\
\hline 02 & K médio, eTh alto, eU médio \\
\hline 01 & K médio, eTh baixo, eU baixo \\
\hline 01 & K alto, eTh médio a baixo, eU médio \\
\hline 01 & K médio, eTh médio a baixo, eU médio a baixo \\
\hline 03 & K médio, eTh médio a baixo, eU médio \\
\hline 01 & K médio, eTh médio a alto, eU médio \\
\hline 01 & K médio, eTh médio a baixo, eU alto \\
\hline
\end{tabular}

CONCLUSÕES A utilização de dados aerogeofísicos na delimitação do arcabouço geológico-estrutural da área de estudo possibilitou a geração de um mapa litogeofísico na escala 1:100.000, onde novas unidades litológicas e lineamentos estruturais foram reconhecidos, além daqueles descritos em trabalhos anteriores.

Com o mapa de lineamentos magnéticos foi possível reconhecer diferentes gerações de estruturas, com direções NW, NS, NE e algumas EW. Os lineamentos de direção NW são interpretados, na literatura, como associados ao desenvolvimento das zonas de cisalhamento responsáveis pelo pico metamórfico regional de fácies anfibolito. Os lineamentos de direção NNE podem estar relacionadas à colocação de corpos graníticos, com metamorfismo termal. Ocorrências auriferas do tipo lode orogenético verificadas na área de estudo são associadas ao desenvolvimento destas zonas de cisalhamento, podendo apresentar relação com as estrututuras de direção NNE devido a associação espacial de algumas ocorrências auríferas com corpos intrusivos (Melo et al. 2001). Extensos enxames de diques máficos do mesozóico são expressos em lineamentos de direção NNE que cortam a área em toda a sua extensão norte-sul.

O mapa de domínios gamaespectrométricos demonstra uma compartimentação das unidades da Província Vila Nova, bem como do Complexo Guianense, sendo mais expressivo na porção centro-sul da área. Apresenta ainda uma gama de corpos plutônicos, até então não mapeados, intrudindo as rochas das unidades supracitadas, com assinatura gamaespectrométrica e geometria que sugerem natureza comum.

Unidades litológicas previamente mapeadas foram redimensionadas baseando-se no seu comportamento gamaespectrométrico, como por exemplo, as Plutônicas 3 e 4 (Granito Amapari), o Enderbito Cobra e o Complexo Máfico Ultramáfico Bacuri. Outras unidades, que não apresentam correlação com o mapa geológico regional disponível, foram identificadas, com destaque para o corpo circular com $10 \mathrm{~km}$ de diâmetro e para a unidade rica em potássio, com alto gradiente magnético e com $54 \mathrm{~km}$ de extensão, localizadas, respectivamente, nas porções oeste e centro-sul da área de estudo.

Agradecimentos Ao Serviço Geológico do Brasil (CPRM), em particular ao Dr. Manoel Barreto, pela disponibilização dos dados aerogeofísicos. Ao Laboratório de Processamento de Informações Georreferenciadas (LAPIG) da UNICAMP e ao Laboratório de Geofísica Aplicada da Universidade de Brasília (LGA-UnB) pelo acesso à infra-estrutura de software e hardware e pela colaboração com o processamento dos dados. À FAPESP pelo apoio concedido através do Auxílio Pesquisa Proc. No. 02/09038-6 e pela bolsa de estudo de Mestrado para L.A. Magalhães. C.R. Souza Filho agradece ao CNPq pela bolsa de Produtividade em Pesquisa. 


\section{Referências}

AVELAR V.G., Lafon J. M., Delor C. 2001. Geocronologia $\mathrm{Pb}-\mathrm{Pb}$ em Zircão e Sm-Nd em Rocha Total da Porção Centro-Norte do Amapá para a evolução geodinâmica do Escudo das Guianas. In: SBG, Simp. Geol. Amazônia, 7, atas, CD-ROM.

Bahia R.B.C., Faraco M.T.L., Monteiro M.A.S., Camozzato E., Oliveira M.A.O. 2004. Folha SA.22-Belém. In: C. Schobbenhaus, J.H. Gonçalves, J.O.S. Santos, M.B. Abram, R.Leão Neto, G.M.M. Matos, R.M. Vidotti, M.A.B.Ramos, J.D.A. Jesus de (eds.) Carta Geológica do Brasil ao Milionésimo, Sistema de Informações Geográficas. Programa Geologia do Brasil. Brasília, CPRM, CD-ROM.

Blum M.L.B. 1999. Processamento e Interpretação de Dados de Geofísica Aérea no Brasil Central e sua Aplicação à Geologia Regional e à Prospecção Mineral. Brasília, Tese de Doutorado, Instituto de Geociências, Universidade de Brasília, 229p.

Cordani U.D., Tassinari C.C.G., TeixeiraW., Basei M.A.S., Kawashita K. 1979. Evolução Tectônica da Amazônia com base nos dados geocronológicos. In: Congresso Geológico Chileno, II, Actas, p. 137-48.

Faraco M.T.L., Marinho P.A.C., Costa E.J.S., Vale A.G., Camozzato E., 2004. Folha NA.22 - Macapá. In: C. Schobbenhaus, J.H. Gonçalves, J.O.S. Santos, M.B. Abram, R. Leão Neto, G.M.M. Matos, R.M. Vidotti (eds.) Carta Geológica do Brasil ao Milionésimo, Sistema de Informações Geográficas. Programa Geologia do Brasil. Brasília, CPRM, CD-ROM.

Lima M.I.C. 2006. Província Estrutural Amazônia Revisada. In: IX Simpósio de Geologia da Amazônia. Atas, CDROM.

Mello L.V. \& Villas R.N.N. 2001. O Depósito Aurífero Amaparí, Amapá: Fluidos Mineralizantes e Tipologia. In: SBG, Simp. Geol. Amazônia, 7, Atas, CD-ROM.

Mello L.V., Villas R.N.N., Soares J.W., Faraco M.T.L. 2001. O Depósito Aurífero Amaparí, Amapá: Rochas Encaixantes, Química Mineral e Metamorfismo. In: SBG, Simp. Geol. Amazônia, 7, atas, CD-ROM.

Milligan P.R. \& Gunn P.J. 1997. Enhancement and Presentation of Airbone Geophysical Data. AGSO Journal of Australian Geology \& Geophysics, 17(2):63-75.

Parro P.S. 1998. Magnetometria e Gamaespectrometria Aerotransportadas na Interpretação Geológico-Estrutural da Região dos Rios Juruena e Teles Pires - MT. Brasília, Dissertação de Mestrado, Instituto de Geociências, Universidade de Brasília. 60p.

Ricci P.S.F., Carvalho J.M.A., Rosa Costa L.T. 2001. Dife- rentes terrenos, com embasamentos geocronologicamente distintos, justapostos por megaestruturas regionais na fronteira Pará/Amapá. In: SBG, Simp. Geol. Amazônia, 7, atas, CD-ROM.

Rosa-Costa L.T., Vasquez M.L., Carvalho J.M.A., Ricci P.S.F., Lafon J.M. 2001. Geocronologia Preliminar do Arqueano e Paleoproterozóico do NW do Pará/SW do Amapá - Escudo das Guianas. In: SBG, Simp. Geol. Amazônia, 7, atas, CD-ROM.

Rosa-Costa LT., Ricci P.S.F., Lafon J.M., Vasquez M.L., Carvalho J.M.A., Klein, E.L., Macambira M.J.B. 2003. Geology and geochronology of Archean and Paleoproterozoic domais of southwestern Amapá and northwestern Pará, Brazil, southestern Guiana shield. In: Géologie de la France, 2-3-4:101-120.

Silva A.A.C. 2003. Processamento, interpretação e integração de dados geológicos e geofísicos da Província Mineral Tapajós. Dissertação de Mestrado, Instituto de Geociências, Universidade de Brasília, 136 p.

Silva A.M. 1999. Integração de dados geológicos e geofísicos utilizando-se uma nova técnica para seleção de alvos para exploração mineral, aplicada ao Greenstone Belt Rio das Velhas, Quadrilátero Ferrífero. Brasília, Tese de Doutorado, Instituto de Geociências, Universidade de Brasília, 195 p.

Tassinari C.C.G. \& Macambira M.J.B. 2004. A evolução tectônica do Cráton Amazônico. In: V. Manteso-Neto, A. Bartorelli, C.D.R. Carneiro, B.B. Brito-Neves (eds.) Geologia do Continente Sul-Americano: evolução da obra de Fernando Flávio Marques de Almeida. São Paulo, Beca. p. 471-485.

Teixeira A.A. 2003. Integração de dados multifontes para exploração de ouro no Greenstone Belt Rio das Velhas, Quadrilátero Ferrífero, MG. Brasília, Dissertação de Mestrado, Instituto de Geociências, Universidade de Brasília, 158 p.

Thurston J.B. \& Smith R.S. 1997. Automatic Conversion of Magnetic Data to Depth, Dip and Susceptibility Constrast Using SPI (TM) Method. Geophysics, 62:807-813.

Vanderhaeghe O., Ledru P., Thieblemont D., Egal E., Cocherie A., Tegyey M., Milesi S.P. 1998. Contrasting mechanism of crustal growth - Geodynamic evolution of the Paleoproterozoic granite-greenstone belts of French Guiana. Precambrian Research., 92(2):165-193.

Manuscrito AE 048/2006 Submetido em 24 de outubro de 2006 Aceito em 03 de agosto de 2007 